\title{
NEURILEMMOMA OF SINONASAL REGION WITH INTRACRANIAL EXTENSION: AN EXTREMELY RARE ENTITY
}

Bijan K. R. Adhikary ${ }^{1}$, Sirshak Dutta², Kaustuv Das Biswas ${ }^{3}$, Soumik Das ${ }^{4}$, Swapan K. R. Ghosh ${ }^{5}$

\section{HOW TO CITE THIS ARTICLE:}

Bijan K. R. Adhikary, Sirshak Dutta, Kaustuv Das Biswas, Soumik Das, Swapan K. R. Ghosh. "Neurilemmoma of Sinonasal Region with Intracranial Extension: An Extremely Rare Entity". Journal of Evolution of Medical and Dental Sciences 2015; Vol. 4, Issue 16, February 23; Page: 2817-2822, D0I: 10.14260/jemds/2015/408

\begin{abstract}
Neurilemmomas are rare in Sino nasal region. Intracranial extension of this tumor from sinonasal region is extremely uncommon entity. Only few case reports are available in existing literature. One such rare case is reported in the present article which also involves the orbit. The case was successfully operated with minimum complication.
\end{abstract}

KEYWORDS: Neurilemmoma, nose, paranasal sinus, intracranial extension.

INTRODUCTION: Neurilemmomas are benign tumors arise from the Schwann cells of peripheral and sympathetic nerves. The terms Neurilemmoma and Schwannoma are often used interchangeably and so as in the present article. Head and neck neurilemmomas are common but nasal cavity or paranasal sinuses are not among the common sites for this entity. Intracranial extension of sinonasal neurilemmomas are extremely uncommon and only few number of such cases reported yet. Simultaneous invasion of cranial cavity and orbit from sinonasal neurilemmomas are even rarer. Sinonasal neurilemmomas has been postulated to be arising from branches of trigeminal nerve and autonomic nerve.[1] One such case is reported in the present article along with literature review.

CASE REPORT: A eighteen years old female patient attended the outpatient department with right sided nasal obstruction for eight years which became bilateral for last two years, along with rhinorrhea and occasional little amount of epistaxis. She was also having gradually progressing proptosis in right side for last two years. The patient gave a history of nasal surgery six years back in a private set up with only temporary relief of her nasal symptom. The histopathology report was neurilemmoma. No other record of that time was available. On external examination of nose there was a scar mark on the right naso-facial groove, suggesting previous surgery through a lateral rhinotomy approach. Anterior rhinoscopy revealed a smooth tan colour mass in right nasal cavity. There was proptosis in right side [figure 1]. Her vision and eye-ball movements were normal. Contrast enhanced C.T. scan showed a large enhancing mass involving almost whole of the nasal cavity, right fronto-ethmoidal region with extension into the right maxillary sinus and also an intracranial extension in frontal lobe of cerebrum.[Figure 2] A significant proptosis was also noted in right side as the mass compressed the orbital structures. Medial maxillectomy was performed with Weber-Fergusson incision. Tumor was removed piecemeal. Lamina papyracea was found to be eroded in the right side, but the periosteum was intact. Anterior skull base was also found to be eroded, more onto the left side along with the posterior wall of the frontal sinus. Per operative CSF rhinorrhoea was encountered after removal of the tumor as there was anterior skull base defect. The defect was repaired in layers with temporalis fascia, septal cartilage and surgicel. Post-operative period was uneventful. There was no post-operative CSF leak. Histopathology revealed hypercellular areas (Antoni A) composed of monomorphic spindle shaped schwann cells forming verocay bodies in 


\section{CASE REPORT}

focal spaces interspersed with hypocellular (Antoni B) areas. Some thick hyaline walled blood vessels are also seen.[Figure 3 \&4] Post-operative MRI was done after three months, which confirmed complete removal of tumour as well as no recurrence.[Figure 5] The patient is doing well after six months of operation.

DISCUSSION: The term 'Schwannoma' has been attributed in the past either for neurofibroma or neurilemmoma. Some authors think both tumors originate from Schwann cells and perineural connective tissue, but others think the first one originates from perineural cells and the latter one from Schwann cells. Verocay in 1910 first described a group of neurogenic tumours; termed as 'neurinomas'.[2] In 1935, Stout proposed that these tumours arose from nerve sheath elements and they were termed 'neurilemmomas. ${ }^{[3]}$ Any nerve which have a schwann cell sheath may give origin to a Schwannoma or Neurilemmoma and so, this neoplasm may develop in almost any part of the body.[4,5] Neurilemmomas may occur anywhere in the body but have a predilection for the head, neck, and flexor surfaces of the upper and lower extremities.[6] $25 \%-40 \%$ of neurilemmomas are found in head and neck region,[7] but sinonasal neurilemmomas are rare entity. Fung et. al. (2008) in a metaanalysis found only 63 cases of nasal cavity neurilemmomas.[6] Only less than $4 \%$ of head and neck cases occurs at sinonasal cavity in the reported literature. ${ }^{[8]}$ The sinonasal schwannomas originate from the ophthalmic and maxillary branches of the trigeminal nerve and the autonomic ganglia, including the parasympathetic fibers of the sphenopalatine ganglion and the sympathetic fibers of the carotid plexus.[9] Of all intra-cranial tumors schwannomas comprises only about $8 \%$ and most of them are vestibular schwannomas.[10] Calcaterra et. al. found no age, sex or race predilection for sinonasal neurilemmomas.[11] Intra cranial or intra orbital extension from sinonasal schwannomas are extremely rare. The patients generally present with non-specific symptoms like any other sinonasal diseases as nasal obstruction, hyposmia, rhinorrea or epistaxis, which causes delay in diagnosis.[9] Proptosis, epiphora, visual problems or cranial nerve palsies are generally late features and indicate extension either in the orbit or cranial cavity. ${ }^{[9]}$ The patients have been often operated for nasal mass without full radiological investigations which gives only temporary relief.[10] Similar incidence occurred in the present case. Intra cranial or intra orbital extension often gives rise to suspicion for malignant neoplasm, but neurilemmoma is a benign tumor and surgery is curative in most of the cases. CT scan and MRI images are non-specific, the features are those of a benign, slow growing tumor of greater signal intensity than polyps or mucoceles.[12]

Complete surgical excision with attempted preservation of vital anatomical structures is considered to be the treatment of choice for sinonasal neurilemmoma.[9] Approaches depend on the location and extension of the tumor. Endoscopic resection, Caldwell Luc approach, lateral rhinotomy, mid-facial degloving or cranio-facial resection are mentioned in literature.[2,9,12,13] In the reported case lateral rhinotomy approach followed by medial maxillectomy was opted as the mass occupied frontoethmoidal region as well as the maxillary sinus. Intracranial part of the tumor was successfully removed with minimum complication. Intra cranial extension of sinonasal neurilemmoma is so rare that only few case reports are published in literature and not a study. [9,10,12,14,15,16]

Sinonasal region is one of the uncommon sub sites of head and neck neurilemmoma. The present case is further uncommon in regard of intracranial extension of a benign tumor, which raises the suspicion of malignant one. Not only intra cranial, the present case is also having feature of orbital involvement due to pressure effect which causes proptosis. In spite of these complicating factors the 
patient was operated successfully without much per-operative complications and uneventful postoperative period.

\section{REFERENCES:}

1. Bhattacharya A, Saha R, Deb J, Mitra S. Schwannoma Presenting as a Recurrent Nasal Mass: A Case Report. International Journal of Oral \& Maxillofacial Pathology; 2013: 4(1): 72-75.

2. Khanna, S.C.Gupta and P.A. Singh. Schwannoma of Maxillary Sinus. Indian Journal of Otolaryngology and Head and Neck Surgery; 2003: 55(2): 132-135.

3. Stout AP. The peripheral manifestations of the specific nerve sheath tumour (neurilemmoma). Am J Cancer; 1935: 24: 751-79. Cited in Prakash S. B, Nishan, Geetha. Sinonasal Schwannoma: a rare cause of nasal obstruction: A case report. Journal of Evolution of Medical and Dental Sciences. 2014; 3(14): 3048-3052.

4. Batsakis J G, Tomors of the peripheral nervous system, ed 2, Baltimore: William \& Wilkins. 1979, 313-333. Cited in Mario G. Siqueira, Erik Jennings, Osmar J. S. Moraes, Marco Tulio S. Santos, Nelci Zanon, Belmiro J. Mattos, Luiz Belmonte Netto. Naso-Ethmoid Schwannoma With Intracranial Extension. Arq Neuropsiquiatr 2001; 59(2-B): 421-423.

5. Rosai J, Ackerman LV. Ackerman's Surgical Pathology, ed 8. St Louis: Mosby, 1996: Vol 2.

6. HS Fung, PWY Lam, TK Tsang, WK Wong, CW Siu, CM Chan, KW Tang and YL Cheung. Nasal Neurilemmoma in a Patient with Neurofibromatosis 2. Journal of Hong Kong College of Radiologists. 2008; 11: 122-125.

7. Putney, F J, Moran, J J, Thomas, G K. Neurogenic tumors of head and neck. Laryngoscope. 1964; 74: 1037-1059.

8. Yu-Chen Cheng, Po-Li ng Sun, Han-Ju ng Chen, Hao-Kuang Wang, Yu-Chang Lee. Benign Schwannoma in the Sphenoid Sinus: Two case report. Chinese Journal of Radiology. 2010; 35: 179-183.

9. Jivianne T. Lee, Lester D R Thompson, Rohit Garg, David B Keschner, Terry Shibuy. Endoscopic Management of Recurrent Anterior Skull Base Schwannoma. International Journal of Otolaryngology and Head \& Neck Surgery. 2013; 2: 52-56.

10. Ravinder Sharma, Isha Tyagi, Deepu Banerjee, Rakesh Pandey. Nasoethmoid schwannoma with intracranial extension. Case report and review of literature. Neurosurgical review. 1998; 21: 5861.

11. Ernesto Pasquini, M.D., Vittorio Sciarretta, M.D., Giovanni Farneti, Antonio Ippolito, Diego Mazzatenta, and Giorgio Frank. Endoscopic Endonasal Approach for the Treatment of Benign Schwannoma of the Sinonasal Tract and Pterygopalatine Fossa. American Journal of Rhinology. 2002, 16, No. 2: 113-118.

12. Mario G. Siqueira, Erik Jennings, Osmar J.S. Moraes, Marco Tulio S. Santos, Nelci Zanon, Belmiro J. Mattos, Luiz Belmonte Netto. Naso-Ethmoid Schwannoma with Intracranial Extension. Arq Neuropsiquiatr 2001; 59(2-B): 421-423.

13. Sharma R, Singh A K, Shambhu B, Reddy N S. Maxillary Sinus Schwannoma Extending to Orbit. Journal of Nepal Medical Association 2003; 42: 100-103.

14. Gupta R, Khurana N, Singh DK, Singh S. Schwannoma of nasal cavity with intracranial extension: A rare but interesting phenomenon in a benign neoplasm. Indian J Pathol Microbiol 2008; 51: 447. 


\section{CASE REPORT}

15. Hanada T, Fukuiwa T, Matsuzaki T, Hanamure Y, Niiro M, Ohyama M. A Rare Case of Nasal Schwannoma with Intracranial Extension. Rhinology. 1997 Dec; 35(4): 181-3.

16. David S. Enion, Alistair Jenkins, John B. Miles and J. V. Diengdoh. Intracranial Extension of a Naso-Ethmoid Schwannoma. The Journal of Laryngology \& Otology. 1991; 105(7): 578-581.

FIGURE 1: Clinical photograph showing the patient with proptosis of right eye.

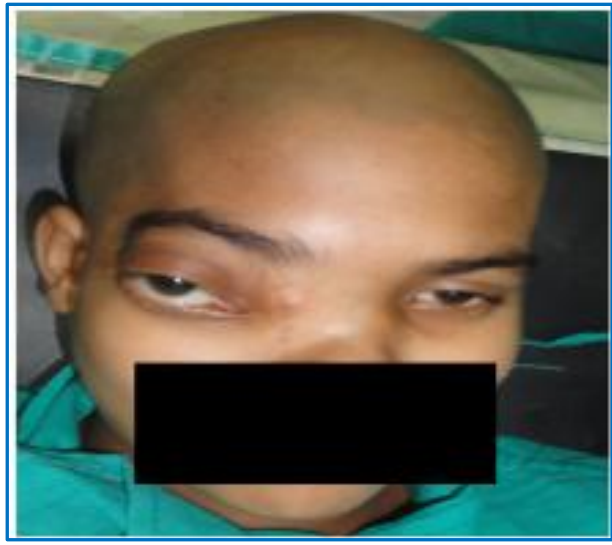

Fig. 1

FIGURE 2: CT scan picture showing enhancing mass involving almost whole of the nasal cavity, right fronto-ethmoidal region with extension into the right maxillary sinus and also an intracranial extension in frontal lobe of cerebrum.

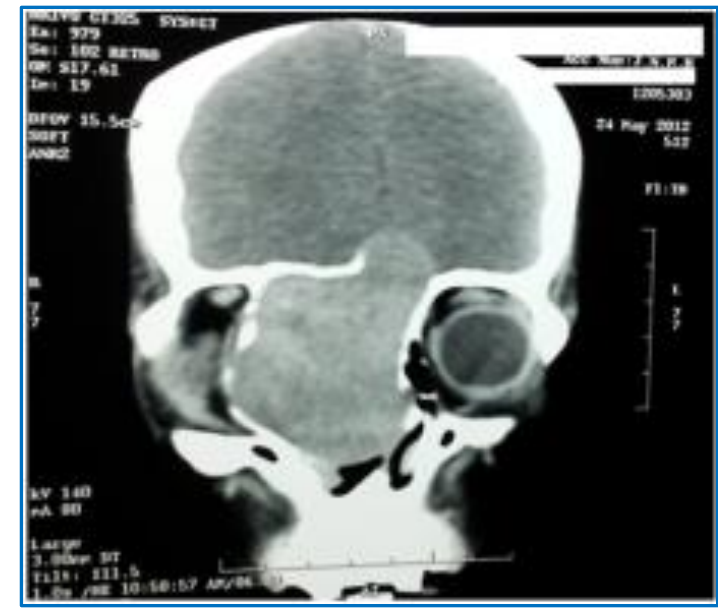

Fig. 2 


\section{CASE REPORT}

FIGURE 3: Photomicrograph showing hypercellular areas (Antoni A) composed of monomorphic spindle shaped schwann cells forming verocay bodies (H \&E stain, 40X).

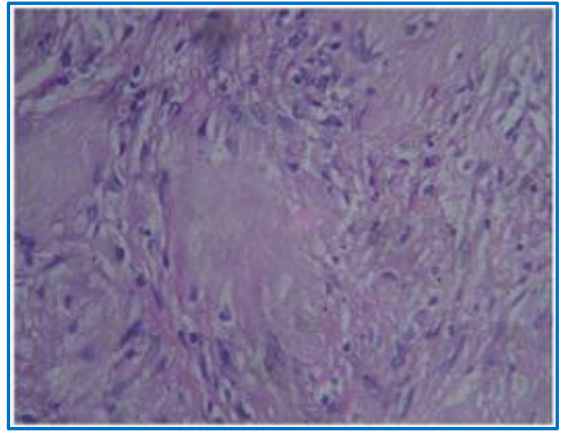

Fig. 3

FIGURE 4: Photomicrograph showing myxoid hypocellular (Antoni B) areas (H \&E stain, 10X).

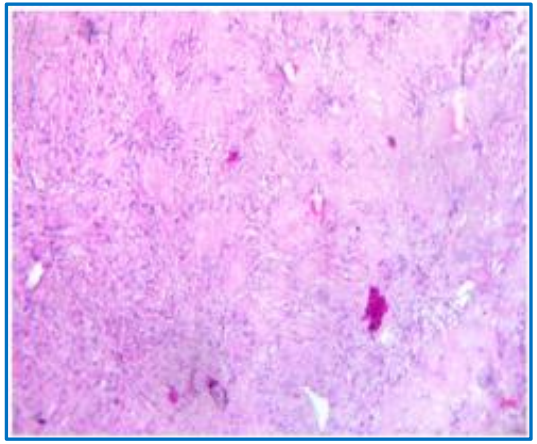

Fig. 4

FIGURE 5: MRI picture done three months post operatively, showing complete removal of tumour \& no recurrence.

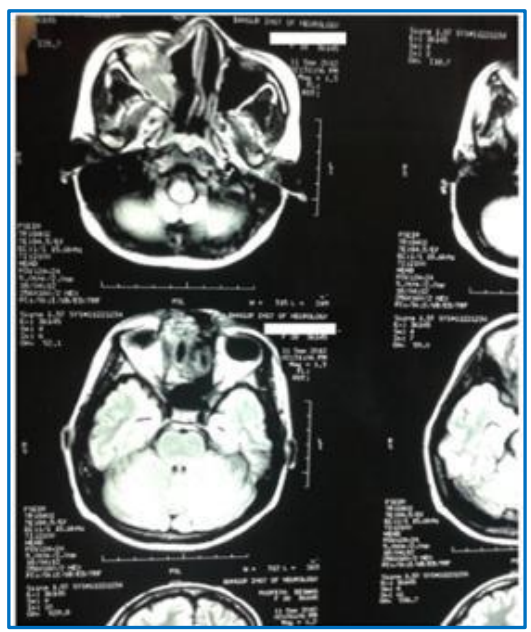

\section{Fig. 5}




\section{AUTHORS: \\ 1. Bijan K. R. Adhikary \\ 2. Sirshak Dutta \\ 3. Kaustuv Das Biswas \\ 4. Soumik Das \\ 5. Swapan K. R. Ghosh}

\section{PARTICULARS OF CONTRIBUTORS:}

1. RMO-CUM-Clinical Tutor, Department of ENT, Medical College and Hospital, Kolkata.

2. RMO-CUM-Clinical Tutor, Department of ENT, Medical College and Hospital, Kolkata.

3. RMO-CUM-Clinical Tutor, Department of ENT, IPGMER \& SSKM Hospital, Kolkata.

4. Associate Professor, Department of ENT, Medical College and Hospital, Kolkata.

\section{FINANCIAL OR OTHER} COMPETING INTERESTS: None
5. Professor, Department of ENT, IPGMER \& SSKM Hospital, Kolkata.

\section{NAME ADDRESS EMAIL ID OF THE CORRESPONDING AUTHOR:}

Dr. Kaustuv Das Biswas,

Avishikta-1, Flat no. -2B-402, 369/1,

Purbachal,

Kalitala Road,

Post Office- Haltu,

Kolkata-700078,

West Bengal.

E-mail: dr.kaustuv.82@gmail.com

Date of Submission: 26/01/2015.

Date of Peer Review: 27/01/2015.

Date of Acceptance: 13/02/2015.

Date of Publishing: 23/02/2015. 